\title{
Plasma treated graphene oxide films: structural and electrical studies
}

\author{
Tianyi $\mathrm{Li}^{1}$, Trupti Patel ${ }^{1}$, Indrani Banerjee ${ }^{2 \#}$, Ruth Pearce-Hill ${ }^{1}$, John Gallop ${ }^{1}$, Ling \\ $\mathrm{Hao}^{1}$ and Asim K Ray ${ }^{2}$ \\ ${ }^{1}$ National Physical laboratory, Teddington, TW11 0LW, UK. \\ ${ }^{2}$ Institute of Materials and Manufacturing, Brunel University London, Uxbridge, Middlesex \\ UB8 3PH, UK
}

\begin{abstract}
The exfoliation of oxygenated functional groups from $60 \mathrm{~W}$ hydrogen plasma treated graphene oxide (GO) films was investigated using X-Ray diffractometric (XRD), Raman spectroscopic and atomic force microscopic (AFM) techniques. The interlayer spacing of the graphene oxide sheets was found from the XRD pattern to decrease from $0.88 \mathrm{~nm}$ to $0.35 \mathrm{~nm}$ after plasma treatment. The reduced intensity ratio of the $D$ and $G$ peaks of the Raman spectra indicates a decrease in the crystallite size of the $\mathrm{sp}^{2}$ domains due to plasma treatment. Atomic force microscope showed the continuous morphology of the plasma treated film. The electrical properties of plasma treated samples spin-coated on silicon were studied using Van Der Pauw and non contacting microwave techniques. The sheet resistivity determined from Van der Pauw measurements was $1.62 \mathrm{M} \Omega / \mathrm{sq}$, yielding the value of $3.1 \mathrm{Sm}^{-1}$ for the bulk conductivity. The charge mobility of $3.8 \mathrm{~m}^{2} \mathrm{~V}^{-1} \mathrm{~s}^{-1}$ has been determined from Hall measurement technique.
\end{abstract}

Keywords: Graphene oxide, graphene, plasma reduction, electrical properties, Van der Pauw, Microwave 


\section{Introduction}

The last decade has seen vast amount of curiosity driven fundamental research to investigate a wide range of interesting mechanical, electrical, optical and thermal properties of graphene $[1,2]$. This two dimensional material has become one of the most promising material for applications like field effect transistors [3, 4], hydrogen storage [5, 6], transparent conductive electrical device fabrication [6, 7] and sensors [8]. However, commercial exploitations of this scientific and technical knowledge depend critically upon the development of scalable manufacturing processes of graphene using cost-effective bottom-up or top-down techniques $[9,10]$. For example, a microwave $(2.45 \mathrm{GHz})$ reactor was successfully employed for the synthesis of single-layer and bilayer graphene sheets in substrate free environment by passing ethanol droplets in the argon plasma [11]. Chemically vapour deposited (CVD) thin graphene films on nickel substrates are found to be of high quality like mechanically cleaved

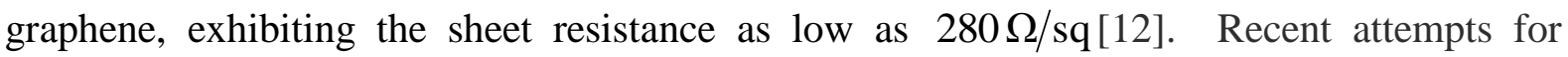
thermal and UV lamination of facile-doped CVD graphene layers on flexible and transparent substrates have been significantly promising for large area opto-electronic device applications [13] Graphene films epitaxially grown on commercially available nominally on-axis oriented wafers of $6 \mathrm{H}-\mathrm{SiC}(0001)$ in an Ar environment under nearly atmospheric pressure are found to be morphologically superior to those formed under vacuum graphitisation, giving higher Hall mobility by a factor of 2 [14]. Reduction of graphene oxide (GO) offers a commercially viable high yield route to solution processing of graphene films from inexpensive raw materials of graphite. Conventionally, a chemical route of reduction using strong reducing agents like hydrazine hydrate $\left(\mathrm{N}_{2} \mathrm{H}_{4}\right)$ or sodium borohydride $\left(\mathrm{NaBH}_{4}\right)$ are used $[15,16]$. . These reagents are highly toxic, hazardous and not environment friendly. Moreover, the chemical reduction processes are often inefficient to complete the exfoliation of oxygenated components. Ar, $\mathrm{H}_{2}$ or ultra-high vacuum thermal annealing process at higher temperature is used for this purpose which again restricts usage of many desirable substrates. Therefore, low temperature green method of reduction processes like flash reduction, electrochemical reduction and plasma reduction is recommended. In contrast, plasma reduction involves low temperature non equilibrium process undergoing chemically pure reactions [17]. Theoretical investigation suggests that the oxygen containing groups Form Island like clusters lying intermixed with the oxygen functionalized atoms $[18,19]$. The hydrogen plasma producing atomic hydrogen may effectively remove these oxygen functional groups in the graphene oxide. The removal of oxygen functional groups is 
therefore likely to enhance the electrical properties of the GO being classified as reduced graphene oxide (rGO).

In the present investigation, commercially available graphene oxide (GO) nanoparticles have been utilised to produce solution processed thin films of GO on silicon substrates. The films have then been reduced by 60 watt RF hydrogen plasma at room temperature in the ordinary laboratory environment. X-Ray diffraction patterns and Raman Spectra have been studied for evaluation of structural changes due to plasma treatment. The Van der Pauw technique has been employed to determine the sheet resistivity and Hall Voltage measurements have been made to determine the carrier density.

\section{Experimental details}

Thin films of GO were prepared using the solution processing technique for characterisations.

\subsection{Preparation of plasma reduced graphene oxide sample}

The graphene oxide solution containing a 40 weight $\%$ dispersion of graphene oxide nanoparticles in water (supplied by Sigma-Aldrich) was drop coated on a silicon substrate which had been previously cleaned with acetone and distilled water. The aqueous solvent was then completely removed by oven drying at $100^{\circ} \mathrm{C}$ in air. The plasma reduced graphene oxide (rGO) was prepared using RF hydrogen plasma operated at 60 watt for 30 minutes. The samples were then used for structural, surface morphological and electrical studies.

\subsection{Characterisation of reduced graphene oxide (rGO) thin films}

The plasma reduced graphene oxide samples were characterized by means of X-Ray diffraction using Bruker D8 advance scanning instrument. $\mathrm{Cu} \mathrm{K}_{\alpha}$ radiation of wavelength $0.15406 \mathrm{~nm}$ was used with the scattering angle varied between $10^{\circ}$ and $90^{\circ}$ at a scanning rate of 0.02 per sec for crystallographic analysis of the samples. The Raman spectra were obtained for glass substrate using Horiba Join Yvonne Lab RAM HR800 with incident laser beam of wavelength $514.5 \mathrm{~nm}$ and $2 \mu \mathrm{m}$ spot size. The surface morphology and film thickness of the samples were studied by Atomic Force Microscope (Bruker ICON system) in tapping mode using Peak Force Quantitative Nano-Electric (PFQNE) Si coated cantilever SiN probe tips at room temperature in the laboratory environment.

\subsection{Electrical measurements}

Thin films of graphene oxide on the $\mathrm{SiO}_{2} / \mathrm{Si}$ substrates for electrical measurements were spincoated at $850 \mathrm{rpm}$ and $2500 \mathrm{rpm}$ in a sequence for $15 \mathrm{sec}$ and $60 \mathrm{sec}$ respectively at room 
temperature. The 2D low frequency van der Pauw measurements was made on square specimens of the go films with electrical contacts at four corners using small quantities of silver loaded electrically conducting paint to determine the sheet resistance $R_{s}$. Two consecutive measurements were performed; a very low current in the order of 10nA from a Keithly current source was applied to two adjacent edges of the sample while the resulting voltage was recorded using a DVM (Rigol) across the two terminals at the opposite edge of the current terminals. Measurements were repeated by sourcing current along each of the rGO film edges and the current was swept from positive to negative values for each connection configuration. Hall measurements were performed on the same specimen in a transverse magnetic field of $0.4 \mathrm{~T}$ by passing a 10nA current between diagonally opposite nodes and recording the voltage across the remaining opposite nodes. In order to obtain the results with a good degree of confidence, experiments were repeated by reversing the source current polarity and magnetic field direction and interchanging of nodes between current sourcing and voltage recoding.

\section{Results and Discussions}

Figure 1 shows the images of the edges of the plasma treated rGO spin coated on silicon ( $\mathrm{Si}$ ) substrate. The colour of the optical image in Figure 1(a) is seen to be blue in areas where the Si substrate is not covered by film deposition. A topographic AFM image in Figure 1(b) was taken from the area marked by a rectangle in Figure 1(a) in order to measure the film thickness. The extracted line profile in Figure 1(c) shows the variation of the thickness over the film surface with the distance from the edge. The film edge thickness is found to be $200 \mathrm{~nm}$ increasing to more than $0.3 \mu \mathrm{m}$ at the centre of the film. For further investigation into the film topography, both optical and AFM images of the centres of the films are presented in Figure 2. The films are continuous but thicker and more non-uniform at the centre with folds appearing as high peaks in the topography maps. The XRD patterns of drop cast fresh and plasma treated graphene oxide are presented in Figure 3. The XRD spectrum of the freshly prepared graphene oxide film in Figure 3(a) shows a single strong intense GO (002) peak at $2 \theta \sim 10^{0}$ corresponding to the interlayer " $\mathrm{d}$ " spacing of $0.88 \mathrm{~nm}$ determined from the Bragg's law [20]. Using Scherrer formula, the crystallite size was estimated to be $5.84 \mathrm{~nm}$ corresponding to the FWHM value of $1.36 \mathrm{~nm}$ for the peak. The intensity of this peak became significantly reduced after plasma treatment. However, the dominant peak at $2 \theta \sim 26.15^{0}$ in Figure 3(b) may be identified with the $\mathrm{sp}^{2}$ graphitic domain of (002) plane [21]. The 
crystallite size is found to be $5.97 \mathrm{~nm}$ which is very close to the value obtained for the untreated sample. The interlayer distance for the graphitic planes of the plasma treated samples is estimated to be $0.35 \mathrm{~nm}$ which compares very well with the conventional value of $0.34 \mathrm{~nm}$ [22]. A large decrease in the interlayer spacing from $0.88 \mathrm{~nm}$ of graphene oxide to $0.35 \mathrm{~nm}$ due to plasma treatment indicates the exfoliation of the oxygenated functional groups from the intercalated graphene oxide sheets leading to the formation of $\mathrm{sp}^{2}$ graphitic domain structures [23]. The small peak at $2 \theta \sim 10^{\circ}$ reveal the presence of some residual oxygenated functional groups in the sample.

The structural changes occurring in the graphene oxide due to plasma treatment are evident from the Raman spectra in Figure 4. The position of the D bands which are characteristic of the presence of defects and translational disorders underwent a large shift from $1348.3 \mathrm{~cm}^{-1}$ to $1357.7 \mathrm{~cm}^{-1}$ due to plasma treatment. The shift due to plasma treatment from $1594.7 \mathrm{~cm}^{-1}$ to $1593.5 \mathrm{~cm}^{-1}$ is, however, significantly small for $\mathrm{G}$ band corresponding to scattering from $\mathrm{E}_{2 \mathrm{~g}}$ mode of $\mathrm{sp}^{2}$ graphitic domain [24]. For interpretation of the effect of plasma treatment on the structural morphology of the sample, the Lorentzian method of curve fitting has been performed for both Raman spectra. The width of $\mathrm{D}$ band is found to increase from $76.12 \mathrm{~cm}^{-1}$ for untreated to $130 \mathrm{~cm}^{-1}$ for plasma treated sample. A similar increase from $60.25 \mathrm{~cm}^{-1}$ to $81.693 \mathrm{~cm}^{-1}$ is also observed for the width of $\mathrm{G}$ band on the plasma treatment. The distance between defects, $L_{D}$ is estimated from the following equation in the form [25]:

$$
L_{D}=\frac{560}{E_{l}^{4}}\left(\frac{I_{D}}{I_{G}}\right)^{-1}
$$

where, $E_{1}$ is the excitation laser energy $(2.54 \mathrm{eV})$ used for the Raman spectroscopy measurements with laser of wavelength $514 \mathrm{~nm}$. A small decrease of $\mathrm{L}_{D}$ from $17 \mathrm{~nm}$ to $16 \mathrm{~nm}$ with plasma treatment is determined from Equation (1) corresponding to the increase in intensity ratio from 0.77 to 0.93 . Similar decrease in $\left(\mathrm{I}_{\mathrm{D}} / \mathrm{I}_{\mathrm{G}}\right)$ has been reported for the reduction of graphene oxide by hydrazine hydrate which corresponds to the decrease in $\mathrm{sp}^{2}$ cluster size resulting from defects, oxygen vacancies or distortions induced in the $\mathrm{sp}^{2}$ domains due to oxygen extraction [26].

Figure 5 shows a set of reproducible current-voltage curves obtained by the van der Pauw measurements on rGO film spin-coated on the silicon substrate. It can be seen from the inset that the reverse polarity sweeps were also made to achieve greater precision by reciprocity for relatively low conducting rGOfilm. A value of the sheet resistance $R_{s}=1.62 \mathrm{M} \Omega / \mathrm{sq}$ is determined from the numerical solution of the transformation equation in the form [27]: 


$$
\exp \left(\frac{\pi R_{A}}{R_{S}}\right)+\exp \left(\frac{\pi R_{B}}{R_{S}}\right)=1
$$

where $\mathrm{R}_{\mathrm{A}}=\frac{R_{1243}+R_{2134}+R_{4312}+R_{3421}}{4}$ and $\mathrm{R}_{\mathrm{B}}=\frac{\mathrm{R}_{1423}+R_{4132}+R_{2314}+R_{3241}}{4}$

Values of resistances such as $\mathrm{R}_{1243}, \mathrm{R}_{1423}$ which correspond to the voltage measured for the current sweep as indicated in the inset of Figure 5 were estimated from slopes of individual linear curves, giving values of $14.9 \mathrm{k} \Omega$ and $1.83 \mathrm{M} \Omega$ for $\mathrm{R}_{\mathrm{A}}$ and $\mathrm{R}_{\mathrm{B}}$, respectively. The present value of the sheet resistance compares well with one obtained for thermally reduced graphene oxide but is two orders of magnitude higher than plasma assisted reduction at low temperature [28]. The bulk conductivity $\sigma$ of RGO film is found to be $3.1 \mathrm{Sm}^{-1}$ from the knowledge that $\sigma=1 /\left(R_{s} t\right)$ where the thickness $t$ is taken to be 200nm [29].

Values of Hall voltage $\mathrm{V}_{\mathrm{H}}$ were recorded for $\mathrm{rGO}$ film in the direction mutually perpendicular to both $10 \mathrm{nA}$ current flow and magnetic field $\mathrm{B}$ of $\pm 0.4 \mathrm{~T}$ and the results are summarised in Table 1. Irrespective of the electrode configurations, the directions of current and magnetic field, $V_{P}$ and $V_{N}$ are found to be negative implying the majority carriers are electrons. Also it is to be noted that voltage values are in satisfactory agreement for all connection configurations, indicating the reliability of the measurements. The area carrierdensity $\mathrm{n}_{\mathrm{s}}$ is estimated to be $2.1 \times 10^{11} \mathrm{~cm}^{2}$ from the knowledge that $\mathrm{n}_{\mathrm{s}}=\frac{\mathrm{IB}}{\mathrm{qV}_{\mathrm{H}}}$ where the Hall voltage $\mathrm{V}_{\mathrm{H}}=11.8 \mu \mathrm{V}$. A value of $37.5 \mathrm{~cm}^{2} \mathrm{~V}^{-1} \mathrm{~s}^{-1}$ is obtained for the mobility $\mu$ from the expression $\mu=\frac{1}{\mathrm{qn}_{\mathrm{s}} \mathrm{R}_{\mathrm{S}}}$.

A sample was similarly prepared on a quartz substrate using the same method and same plasma power treatment. The non-contacting microwave resonator method [30,31] was employed to measure the sheet resistance $R_{s}$ without the need for electrical contacts. The resulting sheet resistance is found to be $500 \mathrm{k} \Omega / \mathrm{sq}$ which is more than one half of the low frequency van der Pauw result. This order of magnitude agreement is reasonable, given the extremely high sheet resistance values, and indicates that the graphene film covers most of the sample surface. The higher value measured by the van der Pauw method may be understood in light of our earlier observation of graphene samples with widely differing sheet resistance [32]. This may also be attributed to the possibility that there are areas to which 
percolation paths between contacts are not linked. Further work is in progress to achieve the consistency of results from two measurement methods.

\section{Conclusions}

Solution processed graphene oxide films have been successfully treated with hydrogen plasma for conversion to reduced graphene oxide. AFM shows that the films are found to be continuous with an edge thickness of $200 \mathrm{~nm}$ which is not affected by plasma treatment time. The interpretation XRD pattern and Raman spectra are consistent with each other, indicating a large decrease in the size of in plane $\mathrm{sp}^{2}$ graphitic domain, increase in edge planes and also increase of disorder in the samples. Plasma treatment may therefore, be efficiently employed as a green method of exfoliation of oxygenated functional groups from graphene oxide films. Two different methods have been used to study the electrical properties of the reduced samples. The reduction process has enhanced the electrical properties of rGO samples.

\section{Acknowledgement}

Dr. Indrani Banerjee is grateful to Commonwealth Association, UK for funding the present research work under the fellowship placement scheme (grant reference INCF-2014-66). Gratitude is due to Dr Lesley Hanna of Wolfson Centre, Brunel University London for help in preparing the manuscript.

\section{Reference:}

[1]. K. S. Novoselov, A. K. Geim, S.V. Morozov, D. Jiang, Y. Zhang, S. V. Dubonos, I. V. Grigorieva, A. A. Firsov, Science, 306, 666 (2004).

[2]. T. Mori, Y Kikuzawa, H. Takeuchi, Org. Electron. 9, 328-332 (2008).

[3]. M. C. Lemme, T. J. Echtermeyer, M. Baus, H. Kurz, IEEE Electron Device Lett 28, 282. (2007)

[4]. J. Su, M. Cao, L. Ren, C. Hu, J. Phys. Chem. C, 115, 14469 (2011)

[5]. D. C. Elias, R. R. Nair, T. M. G. Mohiuddin, S. V. Morozov, P. Blake, M. P. Halsall, A. C. Ferrari, D. W. Boukhvalov, M. I. Katsnelson, A. K. Giem, , K. S. Novoselov, Science 323, 610-613(2009) 
[6]. $\quad$ X. Wang, L. J. Zhi, K. Mullen, Nano Lett., 8, 323-327 (2008)

[7]. S. Watcharotone, D. A. Dikin, S. Stankovich, R. Piner, I. Jung, G. W. B. Dommett, G. Evmenenko, S. E. Wu, S. E. Chen, S. F. Chen, C. P. Liu, S. T. Nguyen, R. S. Ruoff, Nano Lett. 7, 1888 (2007)

[8]. F. Scheldin, A. K. Giem, S.V. Morozov, E. W. Hill, P. Blake, M. I. Katsnelson, K. S. Novoselov, Nat. Mater. 6 ,652-655 (2007).

[9]. Y. Li, and N. Chopra, JOM 67(1) 34-43 (2015)

[10]. Y. Li, and N. Chopra, JOM 67 (1) 44-52 (2015)

[11]. A. Dato, V. Radmilov, Z Lee, J Philips, M. Frenklach, Nano Lett. 8, 2012 (2008).

[12]. K. S. Kim, Y. Zhao, H. Jang, S. Y. Lee, J. M. Kim, K. S. Kim, J. H. Ahn, P. Kim, J. Y. Choi, B. H. Hong, Nature, 457, 706-710 (2009).

[13]. M. H. Kang, W. I. Milne, M. T. Cole, IET Circ. Devices Syst. 9(1) 39 (2015)

[14]. K. V. Emtsev, A. Bostwick, K. Horn, J. Jobst, G. L. Kellog, L. Ley, J. L. McChesney, T. Ohta, S. A. Reshanov, J. Rohrl, E. Rotenberg, A. K. Schmid, D. Waldmann, H. B. Weber, T. Seyller, Nat. Mater. 8, 203-207 (2009).

[15]. S. F. Pei, H. M. Cheng Carbon 50(9) 3210 (2012).

[16]. S. Stankovich, R. D. Piner, X. Q. Chen, N. Q. Wu, S. T. Nguyen, R. S. Ruoff, J. Mater. Chem., B 16, 155 (2006).

[17]. D. Teweldebrhan, A. Balandin, Appl. Phys. Lett. 94, 013101 (2009).

[18]. J. L. Li, K. N. Kudin, M. J. McAllister, R. K. Prud'homme, A. I. Aksay, R. Car, Phys. Rev. Lett. 96, 176101 (2006).

[19]. C. Gomez-Navarro, R. T. Weitz, A. M. Bittner, M. Scolari, A. Mews, M. Burghard, K.Kern, Nano Lett., 7 11, 3499-3503 (2007)

[20]. C. Fu, G. Zhao, H. Zhang, S. Li, Int. J. Electrochem. Sci. 8, 6269-6280 (2013).

[21]. H. Ju, S. H. Choi, S. H. Huh, J. Korean Physical Society, 57(6) 1649-1652 (2010).

[22]. S. Stankovich, A. D. Dikin, D. R. Piner, K. A. Kohlhass, A. Kleinhammes, Y. Wu, S. T. Nguyen, R. S. Ruoff, Carbon, 45, 1558 (2007). 
[23]. X. Tong, H. Wang, G. Wang, L. Wan, Z. Ren, J. Bai, J. Solid State Chem., 184, 982 (2011).

[24] A. C. Ferrari, J. Robertson, J. Phys. Rev. B 61, 14095 (2000).

[25]. L. G. Cancado, A. Jorio, E. H. Martins Ferreira, F. Stavale, C. A. Achete, R. B. Capaz, M. V. O. Moutinho, A. Lombardo, T. S. Kulmala, A. C. Ferrari Nano Lett. 11( 8) 3190 (2011)

[26] V. B. Mohan, R. Brown, K. Jayaraman, D. Bhattacharyya, Mater. Sci. Eng. B-Adv. Funct. Solid-State Mater 193 49-60 (2015)

[27]. J. van der Pauw, Philips Tech Rev. 20, 8 220-4 (1958).

[28] S. W. Lee, C. Mattevi, M. Chhowalla, R. Mohan Sankaran, J. Phys. Chem. Lett. 3, 772-777 (2012).

[29] G Rietveld, C. V. Koijmans, L. C. A. Henderson, M. J. Hall, S. Harmon, P. Warnecke, B. Schumacher, IEEE Trans. Instrum. Meas. 52(2), 449 (2003)

[30]. L Hao, C Mattevi, J Gallop, S Goniszewski, Y Xiao, L Cohen \& N Klein, , Nanotechnology 23285706 (2012),

[31]. O. Shaforost, K. Wang, S. Goniszewski, M. Adabi, Z. Guo, S. Hanham, J. Gallop, L. Hao and N. Klein, J. Appl. Phys. 117, 024501 (2015)

[32]. L Hao, J. Gallop, S Goniszewski, O. Shaforost, N. Klein, R. Yakimova, 'Appl. Phys. Lett., , 103, 123103 (2013). 
List of Tables

Table 1: Summary of Hall measurement for plasma treated spin-coated graphene oxide film on silicon substrate

\begin{tabular}{|c|c|c|c|c|c|c|c|}
\hline \multirow{4}{*}{$\begin{array}{l}\text { Connecti } \\
\text { on } \\
(\mathrm{I}+-, \mathrm{V}+-)\end{array}$} & \multirow{4}{*}{$\begin{array}{c}\mathrm{I} \\
(\mathrm{nA})\end{array}$} & \multicolumn{6}{|c|}{ Magnetic field B (T) } \\
\hline & & \multicolumn{3}{|c|}{+0.4} & \multicolumn{3}{|c|}{-0.4} \\
\hline & & \multicolumn{2}{|c|}{$\begin{array}{l}\text { Terminal reading } \\
(\mathrm{mV})\end{array}$} & \multirow[t]{2}{*}{$\begin{array}{c}\mathrm{V}_{\mathrm{P}}=\left(\mathrm{V}_{+}+\mathrm{V}_{-}\right) / 2 \\
\mathrm{mV})\end{array}$} & \multicolumn{2}{|c|}{$\begin{array}{l}\text { Terminal reading } \\
(\mathrm{mV})\end{array}$} & \multirow[t]{2}{*}{$\begin{array}{c}\mathrm{V}_{\mathrm{N}}=\left(\mathrm{V}_{+}+\mathrm{V}_{-}\right) / 2 \\
\mathrm{mV})\end{array}$} \\
\hline & & $\mathrm{V}_{+}$ & $\mathrm{V}_{-}$ & & $\mathrm{V}_{+}$ & $\mathrm{V}_{-}$ & \\
\hline $\begin{array}{c}\mathrm{I}-13, \mathrm{~V}- \\
24\end{array}$ & 10 & -2.250 & -2.816 & -0.283 & -2.243 & -2.857 & -0.307 \\
\hline $\begin{array}{l}\mathrm{I}-31, \mathrm{~V}- \\
42\end{array}$ & 10 & -2.023 & -2.907 & -0.442 & -2.000 & -2.928 & -0.464 \\
\hline $\begin{array}{c}\text { I-24, V- } \\
13\end{array}$ & 10 & -2.691 & -2.899 & -0.104 & -2.728 & -2.876 & -0.074 \\
\hline $\begin{array}{c}\mathrm{I}-42, \mathrm{~V}- \\
31\end{array}$ & 10 & -2.165 & -2.523 & -0.179 & -2.172 & -2.492 & -0.160 \\
\hline
\end{tabular}


Figure 1: (a) Optical image showing edge of the film, (b) AFM image of the edge of the film (c) line profile of the film indicating an edge height of $200 \mathrm{~nm}$.

Figure 2; (a) Optical image of sample indicating the rough surface topography (b) 3-D AFM image showing changing height of $\sim 1 \mu \mathrm{m}$ at the centre of the film.

Figure 3: $\quad$ XRD pattern for drop-cast graphene oxide film deposited on a glass substrate (a) freshly prepared before (b) RF hydrogen plasma treated at 60watt for 30 minutes.

Figure 4: $\quad$ Raman spectrum for the sample (a) freshly prepared before (b) RF hydrogen plasma treated at 60 watt for 30 minutes.

Figure 5: Current-voltage curves for plasma plasma reduced graphene oxide sample at room temperature with electrode configurations given in Table 1. 

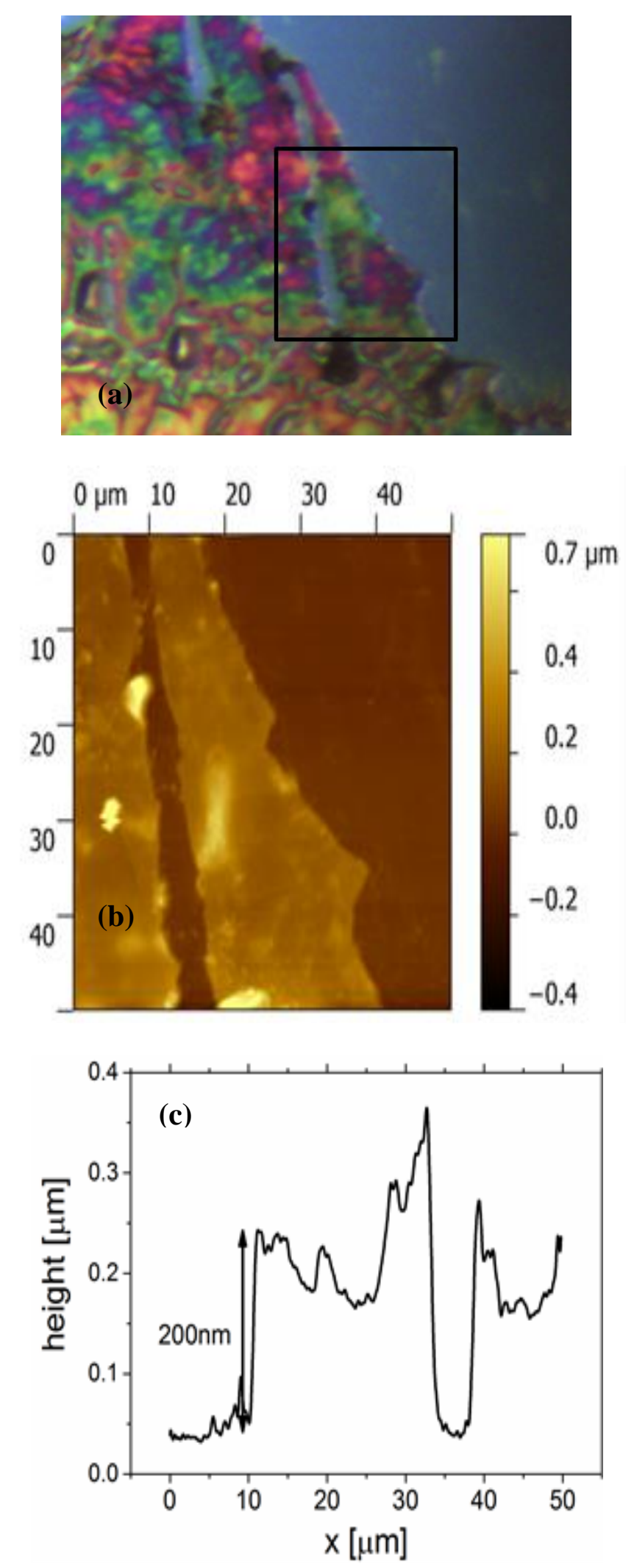

Figure 1: (a) Optical image showing edge of the film, (b) AFM image of the edge of the film (c) extracted line profile of the film indicating an edge height of $200 \mathrm{~nm}$. 

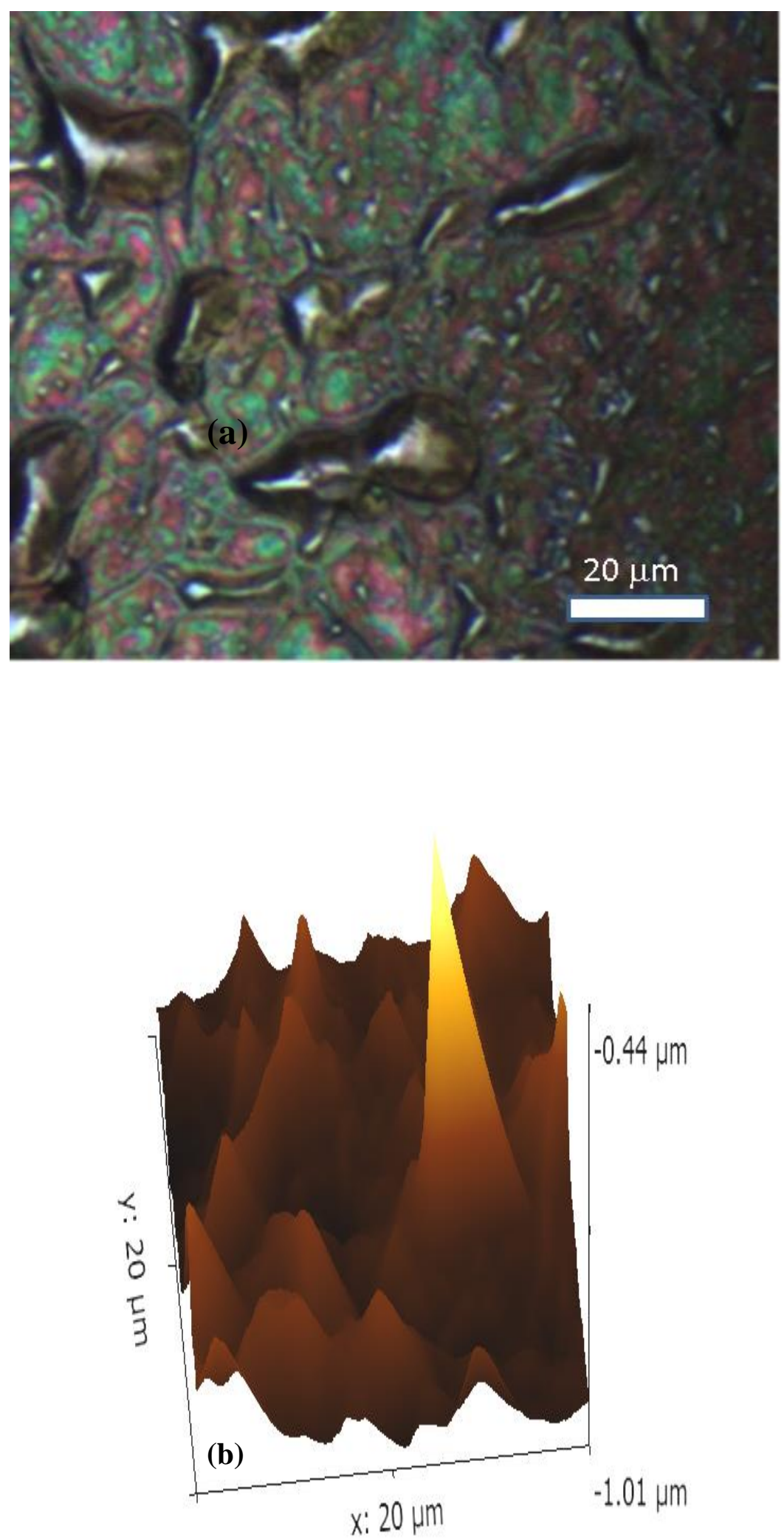

Figure 2 (a) Optical image of sample indicating the rough surface topography (b) 3-D AFM image showing changing height of $\sim 1 \mu \mathrm{m}$ at the centre of the film. 


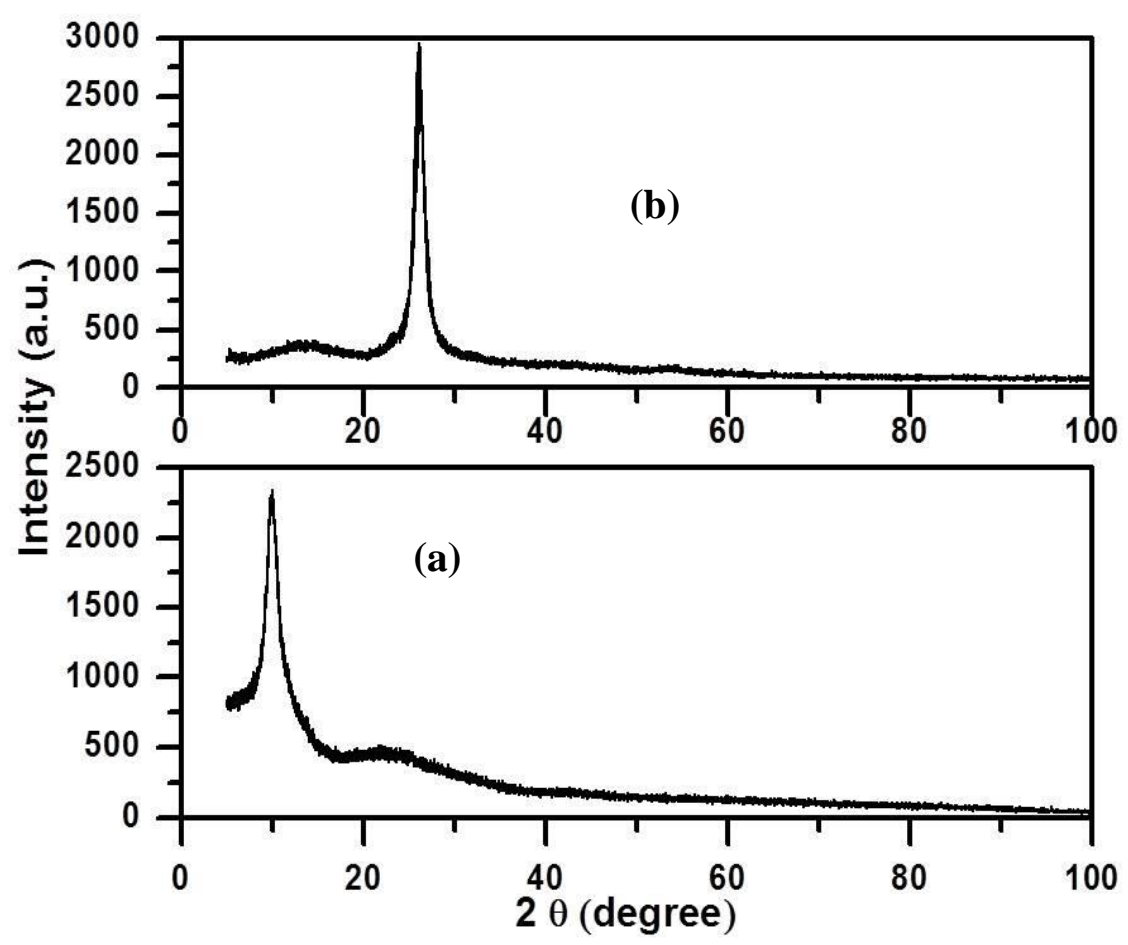

Figure 3: XRD pattern for drop-cast graphene oxide film deposited on a glass substrate (a) freshly prepared before (b) RF hydrogen plasma treated at 60 watt for 30 minutes. 


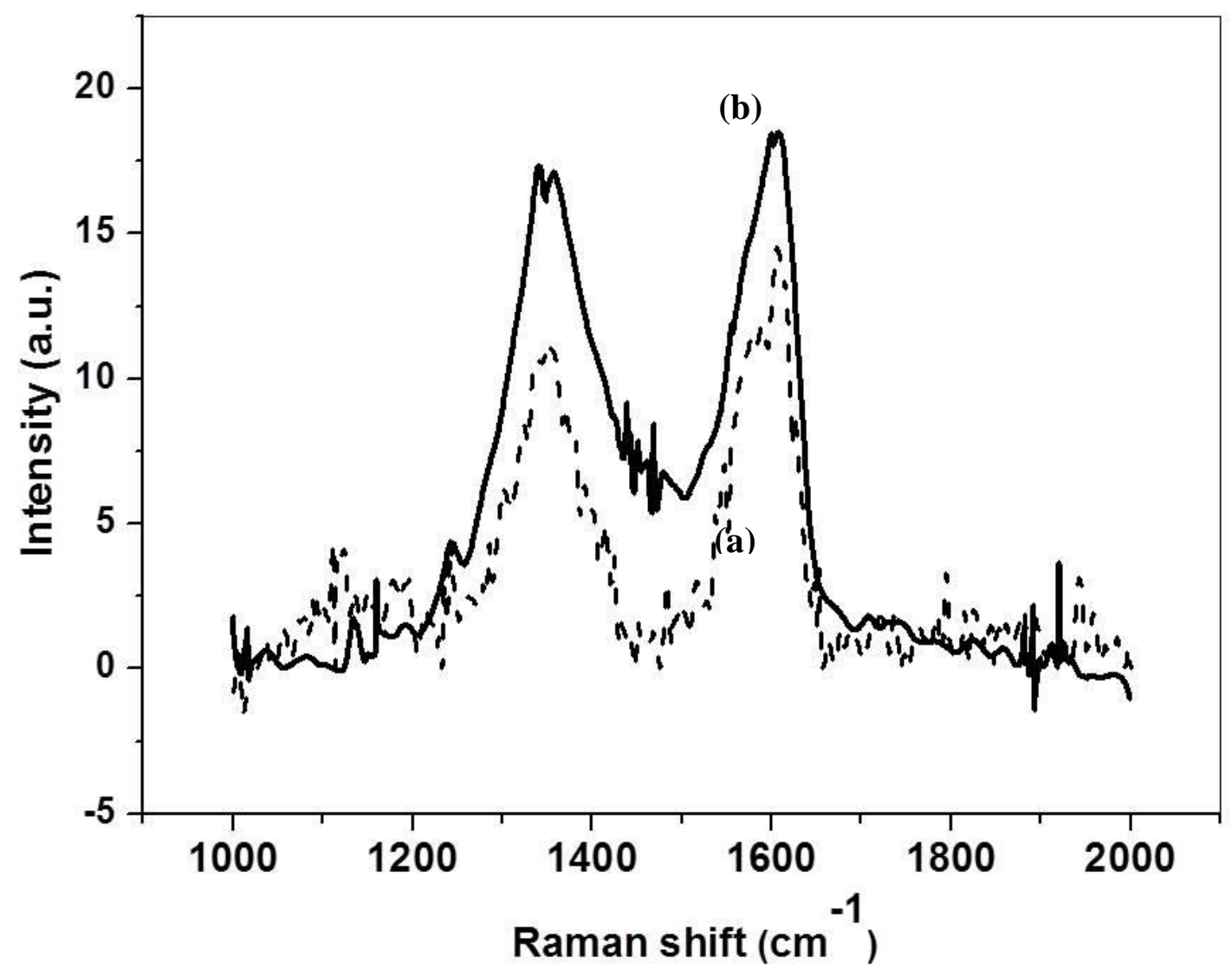

Figure 4: Raman spectrum for the sample (a) untreated (broken line) and (b) plasma treated (solid line). 


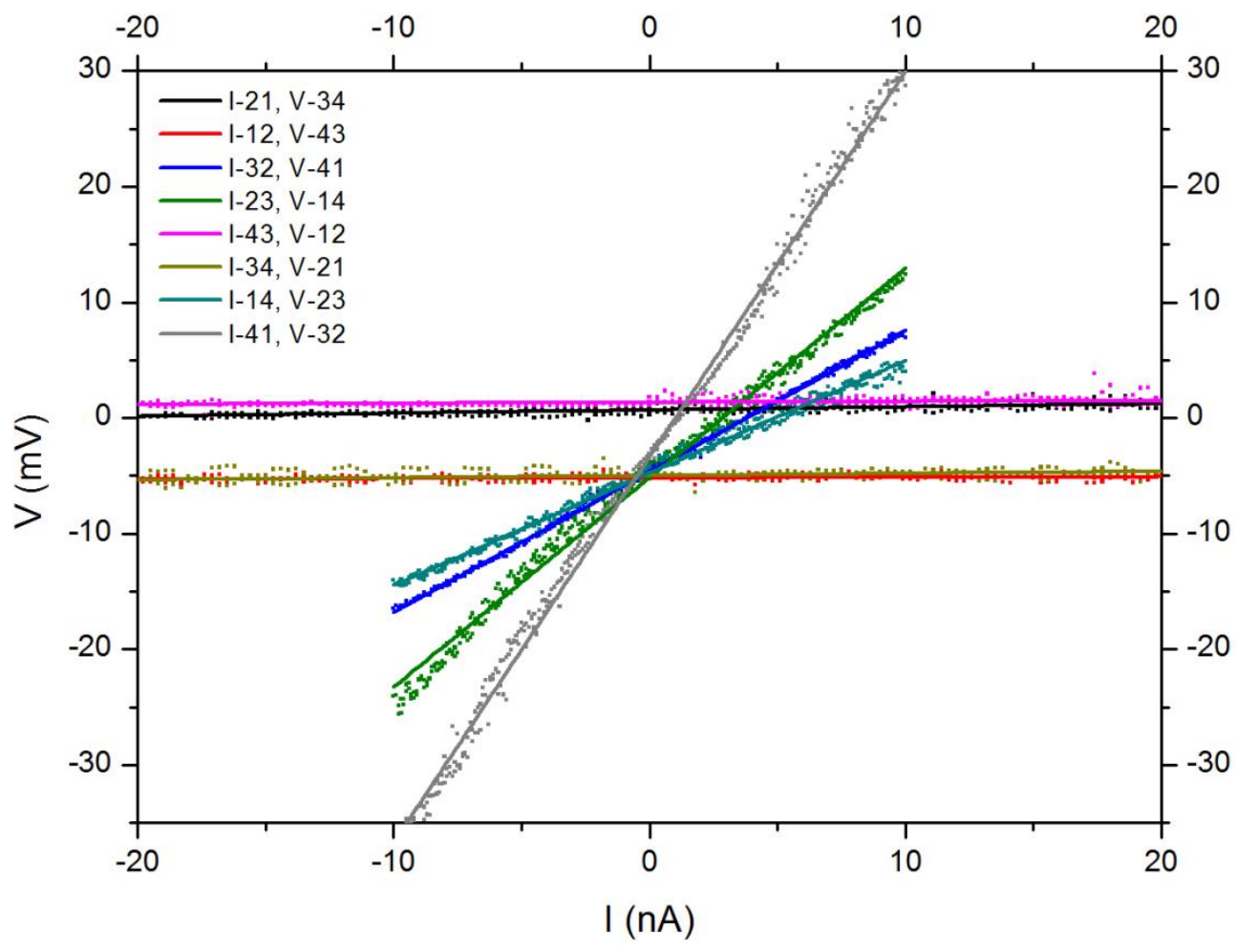

Figure 5: Current-voltage curves for plasma plasma reduced graphene oxide sample at room temperature with electrode configurations given in Table 1. 